\title{
Liquid and Frozen Storage of Agouti (Dasyprocta leporina) Semen Extended with UHT Milk, Unpasteurized Coconut Water, and Pasteurized Coconut Water
}

\author{
W. M. Mollineau, ${ }^{1}$ A. O. Adogwa, ${ }^{2}$ and G. W. Garcia ${ }^{1}$ \\ ${ }^{1}$ The Open Tropical Forage-Animal Production Laboratory (OTF-APL), Department of Food Production (DFP), Faculty of Science and \\ Agriculture, The University of the West Indies (UWI), St. Augustine, Trinidad and Tobago \\ ${ }^{2}$ School of Veterinary Medicine, Faculty of Medical Sciences St. Augustine, Trinidad and Tobago
}

Correspondence should be addressed to W. M. Mollineau, william.mollineau@gmail.com

Received 1 June 2010; Revised 18 June 2010; Accepted 9 August 2010

Academic Editor: Stefan Schlatt

Copyright ( 92011 W. M. Mollineau et al. This is an open access article distributed under the Creative Commons Attribution License, which permits unrestricted use, distribution, and reproduction in any medium, provided the original work is properly cited.

This study evaluated the effects of semen extension and storage on forward progressive motility \% (FPM\%) in agouti semen. Three extenders were used; sterilized whole cow's milk (UHT Milk), unpasteurized (CW) and pasteurized coconut water $(\mathrm{PCW})$, and diluted to 50,100, 150, and $200 \times 10^{6}$ spermatozoa $/ \mathrm{ml}$. Experiment 1: 200 ejaculates were extended for liquid storage at $5^{\circ} \mathrm{C}$ and evaluated every day for 5 days to determine FPM\% and its rate of deterioration. Experiment 2: 150 ejaculates were extended for storage as frozen pellets in liquid nitrogen at $-195^{\circ} \mathrm{C}$, thawed at $30^{\circ}$ to $70^{\circ} \mathrm{C}$ for 20 to 50 seconds after 5 days and evaluated for FPM\% and its rate of deterioration. Samples treated with UHT milk and storage at concentrations of $100 \times 10^{6}$ spermatozoa/ml produced the highest means for FPM\% and the slowest rates of deterioration during Experiment 1. During Experiment 2 samples thawed at $30^{\circ} \mathrm{C}$ for 20 seconds exhibited the highest means for $\mathrm{FPM} \%(12.18 \pm 1.33 \%), 85 \%$ rate of deterioration. However, samples were incompletely thawed. This was attributed to the diameter of the frozen pellets which was $1 \mathrm{~cm}$. It was concluded that the liquid storage method was better for short term storage.

\section{Introduction}

The agouti (Dasyprocta leporina) is a Neotropical edible rodent [1] which belongs to the order Rodentia and the family Dasyproctinae. The female agouti produces up to three parturitions per year in captivity with litter sizes ranging between 1 and 6 [2]. The meat of the agouti is very popular in the Republic of Trinidad and Tobago and is considered a delicacy [1,3]. As estimated 80,000 agoutis are harvested from the local forests annually [3]. Due to harvesting and depletion of the agoutis' habitats, anxieties have arisen concerning the survival of the species on this twin island state. This paper can address this problem by providing information that can be used by animal production personnel to produce agoutis [4] for consumption and release into the wild.
There is little information in the area of preservation of semen from Neo-tropical species although semen from other mammalian species has been extended and stored for decades [5]. Semen has been preserved from domesticated animals [6] using various extenders including cow's milk [7] and coconut milk. Semen was also collected from nondomesticated animals, such as hares (Lepus europaeus) [8]. After storage for 48 hours in liquid nitrogen the $0.25 \mathrm{~mL}$ plastic straws were thawed in a water bath heated to $37^{\circ} \mathrm{C}$ for 30 seconds. The motility in the thawed semen was reduced by $52.63 \%$. However, they concluded that semen collected from the hare by electroejaculation was adequate for cryopreservation.

This study was conducted to evaluate the effects on spermatozoa forward progressive motility percentage in agouti semen extended with UHT milk, unpasteurized coconut 
water, and pasteurized coconut water, after storage in liquid form at $5^{\circ} \mathrm{C}$ and in frozen form in liquid nitrogen at $-195^{\circ} \mathrm{C}$.

\section{Methodology}

2.1. Semen Collection. Animals were anaesthetized with a combination of xylazine and ketamine (dosage $40 \mathrm{mg} / \mathrm{kg}$ live body weight) before electro-ejaculation with an AC1 Electroejaculator (manufactured by Beltron Instruments, Blanco Lane Bryan, TX). Anesthetics were administered by intramuscular injection in the hind quarter using $1 \mathrm{~mL}$ syringes and twenty-two gauge needles.

Semen was collected by electro-ejaculation (EE). Animals were EE after they were overcome by the drug. The stimuli sequence began by applying 2 volts. Voltage was applied for 3 seconds (on period) and halted for 3 seconds (rest or off period). The voltage was then incrementaly increased by 1 volt until the maximum of 12 volts was attained. At each increase the "on" and "off" sequence was repeated. At this point the entire sequence was repeated until the animal ejaculated. Ejaculates were collected in $15 \mathrm{~mL}$ centrifuge tubes. These procedures were approved by the Animal Welfare Committee. This was a modification of the electroejaculation protocol developed by Mollineau et al. [9].

2.2. Criteria for Ejaculate Selection. The forward progressive motility $\%$ (FPM $\%$ ) had to be $\geq 50 \%$ or more, and this was calculated from ten viewing fields for each sample. Spermatozoa concentration had to be $\geq 100 \times 10^{6}$ spermatozoa $/ \mathrm{mL}$. Ejaculate volume had to be $\geq 0.2 \mathrm{~mL}$. All microscopic semen parameters were observed at a magnification of $40 \mathrm{X}$.

2.3. Animals. Animals were caged reared in an intensive agouti production unit at the university's farm and were proven sires between 2 to 3 years of age. Two weeks prior to the experiments animals were randomly selected and housed in individual cages (width $=46 \mathrm{~cm}$, length $=60 \mathrm{~cm}$, and height $=46 \mathrm{~cm}$ ), which allowed for easier handling. This served to reduce the stresses associated with capturing the animals. Agoutis were fed ad lib with rabbit pelleted feed (17\% crude protein, $2.5 \%$ crude fat, and 15\% crude fibre) (manufactured by Master Mix of Trinidad Limited, Republic of Trinidad and Tobago) and given clean, fresh water daily. Animals were fasted for 12 hours prior to electroejaculation.

2.4. Semen Extenders. Ultrahigh temperature (UHT) whole cow's milk, unpasteurized coconut water (CW) and pasteurized coconut water (PCW) were used as semen extenders. The coconut water was first strained by running it through a piece of Indian cotton cloth. It was then used to extend the semen either pasteurized or unpasteurized. Coconut water was pasteurized by boiling for 15 minutes at $65^{\circ} \mathrm{C}$. Extenders were frozen in $25 \mathrm{~mL}$ aliquots in plastic bottles. Ejaculates were diluted with the particular semen extender to 50, 100, 150 , and $200 \times 10^{6}$ spermatozoa $/ \mathrm{mL}$ at $18-21^{\circ} \mathrm{C}$. Fir,st one half of the required volume of semen extender was slowly added to the ejaculate. After 20 minutes the other half was added. This was done to minimize osmotic shock to the spermatozoa.

\subsection{The Two Experiments}

Experiment 1. Two hundred agouti ejaculates met the quality requirements, representing $71.4 \%$ of all ejaculates collected from 20 males over a 20 -week period. Two ejaculates were collected daily from two males and each animal was electroejaculated every 7 days. Ejaculates were sequentially assigned an extender treatment until the desired quota (320 extended samples) for each extender treatment was reached. Ejaculates were extended to $50,100,150$, or $200 \times 10^{6}$ spermatozoa/mL treatments until the desired quota $(80$ extended samples) for each concentration treatment was reached depending on the initial volume and spermatozoa concentration of the ejaculates. Nine hundred and sixty samples were extended from the 200 ejaculates collected and stored at $5^{\circ} \mathrm{C}$. The 960 samples included 320 samples extended with each of the three extenders. Each of these 320 samples included 80 samples with each of the four spermatozoa concentrations. Ejaculate, semen extender, and all equipments used were cooled to $18-21^{\circ} \mathrm{C}$. The aliquots were cooled to $5^{\circ} \mathrm{C}$ over one hour by placing them into a $200 \mathrm{~mL}$ beaker containing $50 \mathrm{~mL}$ of cooled water $\left(18-21^{\circ} \mathrm{C}\right)$, which was then placed into a $5^{\circ} \mathrm{C}$ refrigerator. Samples were filled into $0.25 \mathrm{~mL}$ safe lock microtubes and stored at $5^{\circ} \mathrm{C}$. The FPM\% and the rate of deterioration of FPM\% of samples were evaluated every 24 hours for 5 days.

Experiment 2. This followed the same format as Experiment 1 however the sample size per treatment was lower, 50 samples were used, and samples were stored in frozen pellets in liquid nitrogen $\left(-195^{\circ} \mathrm{C}\right)$. The FPM\% and the rate of deterioration of FPM\% of samples were evaluated after 5 days.

2.6. Thawing. Samples were thawed in a water bath heated to temperatures of $30^{\circ}, 40^{\circ}, 50^{\circ}, 60^{\circ}$, or $70^{\circ} \mathrm{C}$ for $20,30,40$, or 50 seconds.

2.7. Statistical Analysis. The experimental design was a 3 (extenders) by 4 (spermatozoa concentrations) factorial design. Statistical analysis was performed with Microsoft Excel 2007. Analysis included means, standard error of the means, and ANOVA (analysis of variances). ANOVA is a statistical method for making simultaneous comparisons between two or more means. $P$-values less than .05 were considered significant; liquid storage $n=960$; frozen storage $n=600$. The rate of deterioration for FPM\% over time was calculated based on the initial FPM\% of the ejaculate. The data for the various spermatozoa concentrations for each extender was pooled.

\section{Results}

3.1. Experiment 1. Initial ejaculate means and ranges during Experiment 1 for ejaculate volume were $0.26 \pm 0.01 \mathrm{~mL}$, range 
TABLE 1: Data table for Figure 1 listing means \pm SD for FPM\% over time.

\begin{tabular}{|c|c|c|c|c|c|}
\hline \multirow{2}{*}{ Extenders/concentrations } & \multicolumn{5}{|c|}{ Time } \\
\hline & Day 1 & Day 2 & Day3 & Day 4 & Day 5 \\
\hline UHT 50 & $55.5 \pm 6.99$ & $42.5 \pm 18.08$ & $32.86 \pm 16.17$ & $22.86 \pm 10.55$ & $12.14 \pm 4.83$ \\
\hline UHT 100 & $59.5 \pm 7.75$ & $50.5 \pm 6.75^{*}$ & $40.5 \pm 6.75$ & $29.5 \pm 7.78$ & $22.0 \pm 6.24$ \\
\hline UHT 150 & $55.0 \pm 16.41$ & $45.63 \pm 21.21$ & $34.38 \pm 15.32$ & $25.63 \pm 10.49$ & $13.75 \pm 9.19$ \\
\hline UHT 200 & $52.5 \pm 10.06$ & $44.55 \pm 4.12$ & $33.5 \pm 6.58$ & $18.0 \pm 8.43$ & $20.0 \pm 3.5$ \\
\hline CW 50 & $39.5 \pm 4.92$ & $32.0 \pm 17.35$ & $29.0 \pm 12.74$ & $15.0 \pm 9.72$ & $8.3 \pm 6.58$ \\
\hline CW 100 & $54.0 \pm 12.35$ & $40.0 \pm 22.9$ & $26.25 \pm 17.87$ & $20.0 \pm 11.65$ & $5.0 \pm 8.16$ \\
\hline CW 150 & $53.5 \pm 7.91$ & $46.5 \pm 17.91$ & $35.0 \pm 16.87$ & $18.0 \pm 10.66$ & $5.0 \pm 13.13$ \\
\hline CW 200 & $40.0 \pm 18.59$ & $34.0 \pm 17.55$ & $29.0 \pm 9.56$ & $20.0 \pm 9.66$ & $10.0 \pm 6.32$ \\
\hline PCW 50 & $56.5 \pm 14.99$ & $41.86 \pm 14.68$ & $28.75 \pm 16.53$ & $8.7 \pm 10.66$ & $5.0 \pm 6.85$ \\
\hline PCW 100 & $59.5 \pm 16.17$ & $45.5 \pm 20.01$ & $29.0 \pm 17.2$ & $13.0 \pm 11.05$ & $5.0 \pm 6.26$ \\
\hline PCW 150 & $45.0 \pm 12.65$ & $32.1 \pm 23.69$ & $26.0 \pm 17.03$ & $15.0 \pm 14.49$ & $5.0 \pm 10.07$ \\
\hline PCW 200 & $40.0 \pm 14.94$ & $37.0 \pm 20.45$ & $25.0 \pm 16.84$ & $10.0 \pm 10.75$ & $5.0 \pm 7.47$ \\
\hline
\end{tabular}

TABLE 2: lists the mean rates of deterioration and SD for FPM\% where the various spermatozoa concentrations of the various extenders over time are pooled.

\begin{tabular}{|c|c|c|c|c|c|}
\hline \multirow{2}{*}{ Extenders } & \multicolumn{5}{|c|}{ Time } \\
\hline & Day 1 & Day 2 & Day 3 & Day 4 & Day 5 \\
\hline \multirow{2}{*}{ UHT Milk } & $15.70 \pm 3.72$ & $36.84 \pm 3.90$ & $54.36 \pm 3.28$ & $71.39 \pm 2.74$ & $90.21 \pm 2.32$ \\
\hline & $\mathrm{SD}=23.51$ & $\mathrm{SD}=24.64$ & $\mathrm{SD}=20.72$ & $\mathrm{SD}=17.35$ & $\mathrm{SD}=14.70$ \\
\hline \multirow{2}{*}{$\mathrm{CW}$} & $18.96 \pm 3.30$ & $52.51 \pm 5.83$ & $64.55 \pm 4.70$ & $79.24 \pm 3.06$ & $89.59 \pm 2.54$ \\
\hline & $\mathrm{SD}=20.88$ & $\mathrm{SD}=36.90$ & $\mathrm{SD}=27.71$ & $\mathrm{SD}=19.35$ & $S D=16.07$ \\
\hline \multirow{2}{*}{ PCW } & $19.47 \pm 4.53$ & $50.22 \pm 5.60$ & $67.85 \pm 4.73$ & $81.25 \pm 3.08$ & $92.02 \pm 1.87$ \\
\hline & $\mathrm{SD}=28.64$ & $\mathrm{SD}=35.43$ & $\mathrm{SD}=29.90$ & $\mathrm{SD}=19.45$ & $\mathrm{SD}=11.84$ \\
\hline
\end{tabular}

0.10 to $0.60 \mathrm{~mL}$; sperm concentration was $635.90 \pm 42.20 \times$ $10^{6}$ spermatozoa/mL with a range of 130.0 to $2,440.0 \times$ $10^{6}$ spermatozoa $/ \mathrm{mL}$. The rates of deterioration and the standard deviations (SDs) in FPM\% over time for samples extended with the various extenders are listed in Table 1.

Samples extended with UHT milk recorded the slowest rate of deterioration for FPM\% over time (Table 2). The survival of spermatozoa was more dependent on the UHT milk than the other extenders. Such samples showed the best survival rates over time. There were significant differences among the various stored concentrations $(P=$ $.004)$, where samples diluted to concentrations of $100 \times$ $10^{6}$ spermatozoa/mL and extended with UHT milk produced the best results over time (Figure 1).

3.2. Experiment 2. Initial ejaculate means and ranges during Experiment 2 for ejaculate volume were $0.29 \pm 0.04 \mathrm{~mL}$, range 0.10 to $1.00 \mathrm{~mL}$; and spermatozoa concentration was $697.7 \pm 12.1 \times 10^{6}$ spermatozoa $/ \mathrm{mL}$, with a range of 140.0 to $1,410.0 \times 10^{6}$ spermatozoa/mL, and FPM\% was $61.92 \pm$ $0.32 \%$, with a range of 50 to $85 \%$.

Interactions of thawing temperatures and thawing times also had significant effects on the frozen-thawed FPM\% $(P=.000)$. Higher temperatures and longer exposure times increased the rate of deterioration of FPM\%. The

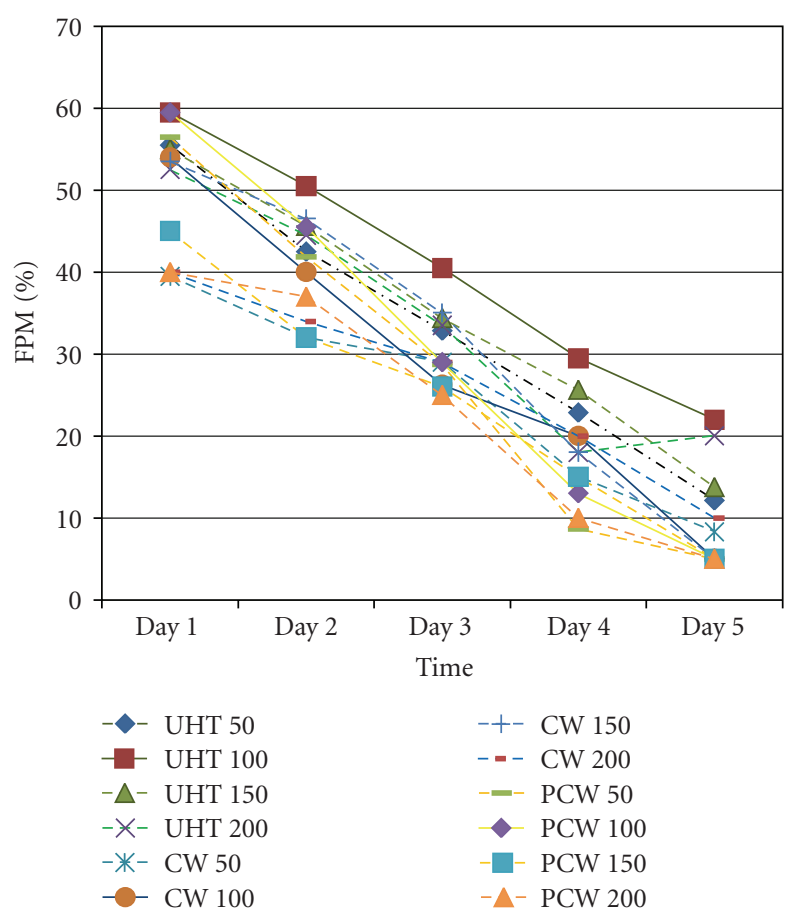

FIgure 1: displays means and SD for FPM\% for the various extenders at the various concentrations over time. 
highest mean frozen-thawed FPM\% was $12.18 \pm 1.33$ and this was obtained when samples were exposed to a thawing temperature of $30^{\circ} \mathrm{C}$ for 20 seconds. However, these pellets were incompletely thawed. The rate of deterioration in FPM\% was 85\% after thawing.

\section{Discussion}

There was significant $(P<.05)$ variation among the various extenders used in Experiment 1. Sharma and Tomar [10] also observed a significant difference among the various semen extenders used to dilute Murrah buffaloes semen which were stored at $5^{\circ} \mathrm{C}$. The reason that samples extended with UHT milk showed the slowest rate of deterioration over time (Figure 1) could be attributed to possible physiological differences between the effects of the various extenders on the survival of the spermatozoa as suggested by Sharma and Tomar [10].

During Experiment 1 it was observed that the stored spermatozoa concentration had significant $(P<.05)$ effects on the survival of spermatozoa (Table 1). Ashworth et al. [11] observed that spermatozoa death was strongly dependent on spermatozoa concentration. At the higher stored spermatozoa concentrations of $150 \times 10^{6}$ spermatozoa $/ \mathrm{mL}$ and $200 \times 10^{6}$ spermatozoa/mL the energy source (fructose) in the stored volume of extended semen may not have been sufficient to provide adequate energy supplies to the spermatozoa at these concentrations for the longer periods of time. Cerovsky [12] and Čerovský [13] also indicated lower survival rates for semen samples containing higher spermatozoa concentrations. It was also indicated by Cerovský [13] that higher spermatozoa survival rates were recorded at lower concentrations. Thus higher FPM\% means were observed for spermatozoa concentrations of $100 \times 10^{6}$ spermatozoa $/ \mathrm{mL}$.

Spermatozoa were also observed forming rosettes. This may act as a means of spermatozoa survival [14]. Lower spermatozoa concentrations may affect the formation of effective rosettes. Joyal et al. [15] also observed that motility percentage declined as the spermatozoa concentrations decreased. Hence this is the reason why at $50 \times 10^{6}$ spermatozoa/mL the mean FPM\% was less than at $100 \times 10^{6}$ spermatozoa/mL.

The means for frozen-thawed FPM\% were low. Thus the rate of deterioration for FPM\% for frozen-thawed agouti semen was higher $(85 \%)$ than the frozen-thawed motility rate of $52.63 \%$ for hare semen as reported by Kozdrowski et al [8]. However the samples in Experiment 2 were not completely thawed. Only at $70^{\circ} \mathrm{C}$ and the longer periods (40 and 50 seconds) did complete thawing occur, but the FPM\% was below 1\%. Failure of samples to have thawed completely could be attributed to the diameter $(1 \mathrm{~cm})$ of the storage pellets. Nakagata et al. [16] successfully thawed wild mice semen stored at $-195^{\circ} \mathrm{C}$ in $0.25 \mathrm{~mL}$ plastic straws in a water bath maintained at $20-24^{\circ} \mathrm{C}$ for five minutes. Kozdrowski et al. [8] also stored extended hare semen in $0.25 \mathrm{~mL}$ plastic straws. These researchers did achieve complete thawing in a water bath of $37^{\circ} \mathrm{C}$ for 30 seconds. The larger diameter of the frozen pellets could have presented more resistance to heat penetrating throughout the sample than with the $0.25 \mathrm{~mL}$ straws. Therefore the samples were incompletely thawed, and only spermatozoa at the periphery were thawed and possessed very low motility. Therefore leaving the samples for longer periods only destroyed more of the viable spermatozoa. The spermatozoa at the periphery moving inwards were exposed to longer heat periods. It is recommended that more research be conducted in this area to develop a protocol for thawing extended agouti semen stored in frozen pellets.

\section{Conclusion}

The liquid storage method for storing extended agouti semen is recommended for short-term storage over the frozen storage method. Frozen storage should be better for longterm storage. However more research in this area is required to identify more effective protocols.

\section{Acknowledgment}

The authors sincerely thank Mr. Greshon "Blueboy" Maurice and Mrs. Elecia Henry for their technical assistance.

\section{References}

[1] W. M. Mollineau, G. W. Garcia, D. Samayah, W. Kissoonsingh, and A. Procope-Garcia, "The wildlife industry in Trinidad: a case study towards developing a sustainable industry model for a small Twin Island State (Trinidad and Tobago)," in Proceedings of the Conference on Managing Space for Sustainable Living in Small Island Development States, University of the West Indies, St. Augustine, Trinidad and Tobago, November 2000.

[2] P. Dollinger, R. Baumgartner, E. Isenbugel, N. Pagan, H. Tenhu, and F. Weber, Husbandry and Pathology of Rodents Lagomorphs in Swiss Zoos, Swiss Federal Veterinary Offic, Berne-Liebefeld, Switzerland, 2001.

[3] A. Roopchand, Wildlife and the oil industry: catshill reserve a case study, M.S. thesis Student project, Department of Food Production, Faculty of Science and Agriculture, University of the West Indies, St. Augustine, Trinidad and Tobago, 2002.

[4] R. C. L. Brown-Uddenberg, G. Garcia, Q. Baptiste, T. Counand, A. Adogwa, and T. Sampson, The Agouti [Dasyprocta leporine, D. aguti] Booklet \& Production Manual. Wildlife Farmers' and Producers' Booklet, GWG Publications, St. Augustine, Trinidad and Tobago, 2003.

[5] E. S. E. Hafez, "Semen evatuation," in Reproduction in Farm Animals, pp. 405-423, Lea \& Febiger, Philadelphia, Pa, USA, 6th edition, 1993.

[6] T. A. A. Khalifa and B. E. El-Saidy, "Pellet-freezing of Damascus goat semen in a chemically defined extender," Animal Reproduction Science, vol. 93, no. 3-4, pp. 303-315, 2006.

[7] A. J. Gutierrez, R. W. Cosme, C. J. A. Jimenez, and G. J. A. Ramirez, "Coconut milk, bovine fetal serum, Aloe vera and their combinations for cryopreservation of ovine semen," Archivos de Zootecnia, vol. 55, no. 209, pp. 101-104, 2006.

[8] R. Kozdrowski, A. Dubiel, and M. Siemieniuch, "Preliminary studies on cryopreservation of hare (Lepus europaeus Pallas, 
1778) semen," Animal Reproduction Science, vol. 93, no. 3-4, pp. 379-382, 2006.

[9] W. M. Mollineau, A. O. Adogwa, and G. W. Garcia, "A preliminary technique for electro-ejaculation of agouti (Dasyprocta leporina)," Animal Reproduction Science, vol. 108, no. 1-2, pp. 92-97, 2008.

[10] K. B. Sharma and N. S. Tomar, "Studies on the effect of glycerol on the keeping quality of bovine semen at $5^{\circ} \mathrm{C}$," Indian Veterinary Journal, vol. 61, no. 6, pp. 496-500, 1984.

[11] P. J. C. Ashworth, R. A. P. Harrison, N. G. A. Miller, J. M. Plummer, and P. F. Watson, "Survival of ram spermatozoa at high dilution: protective effect of simple contituents of culture media as compared with seminal plasma," Reproduction, Fertility and Development, vol. 6, no. 2, pp. 173-180, 1994.

[12] J. Cerovsky, "The effect of degree of boar semen dilution on survival rate of spermatozoa," Živočišná Výroba, vol. 27, no. 8, pp. 619-626, 1982.

[13] J. Čerovský, “The relationship of survival of boar spermatozoa with sperm concentration in undiluted semen and at different degrees of dilution," Vedecké Práce Výzkumného Ústavu pro Chov Prasat v Kostelci nad Orlicí, vol. 6, no. 1, pp. 103-112, 1986.

[14] W. V. Holt, L. M. Penfold, S. D. Johnston et al., "Cryopreservation of macropodid spermatozoa: new insights from the cryomicroscope," Reproduction, Fertility and Development, vol. 11, no. 6, pp. 345-353, 1999.

[15] S. M. Joyal, B. W. Kennedy, and J. N. Wilkins, "Boar, breed and environmental effects on motility of frozen-thawed spermatozoa," Annual Report, Department of Animal and Poultry Science, Centre for Genetic Improvement of Livestock, Ontario Agricultural College, University of Guelph, Guelph, Canada, 1986.

[16] N. Nakagata, S. Ueda, K. Yamanouchi et al., "Cryopreservation of wild mouse spermatozoa," Theriogenology, vol. 43, no. 3, pp. 635-643, 1995. 

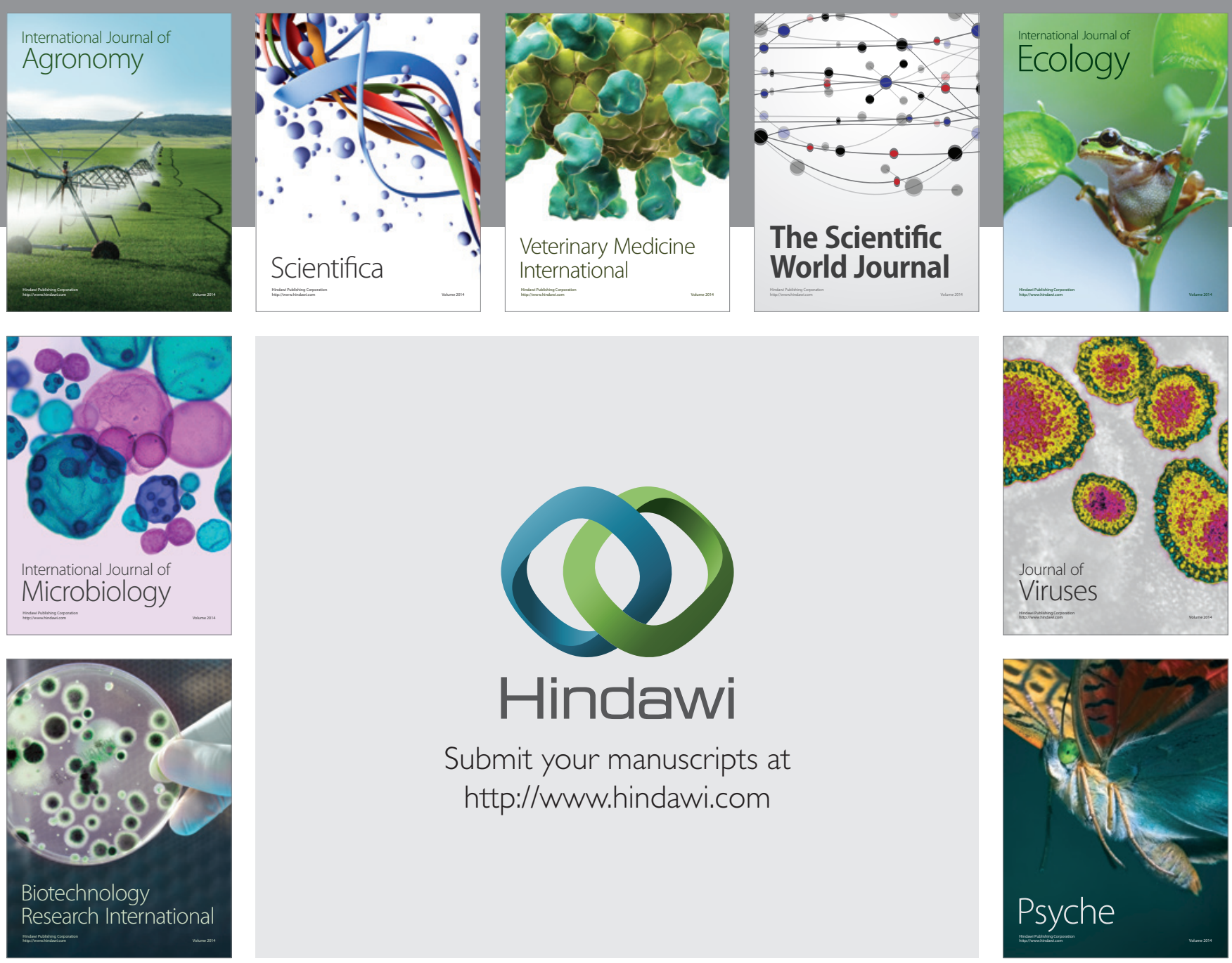

Submit your manuscripts at

http://www.hindawi.com
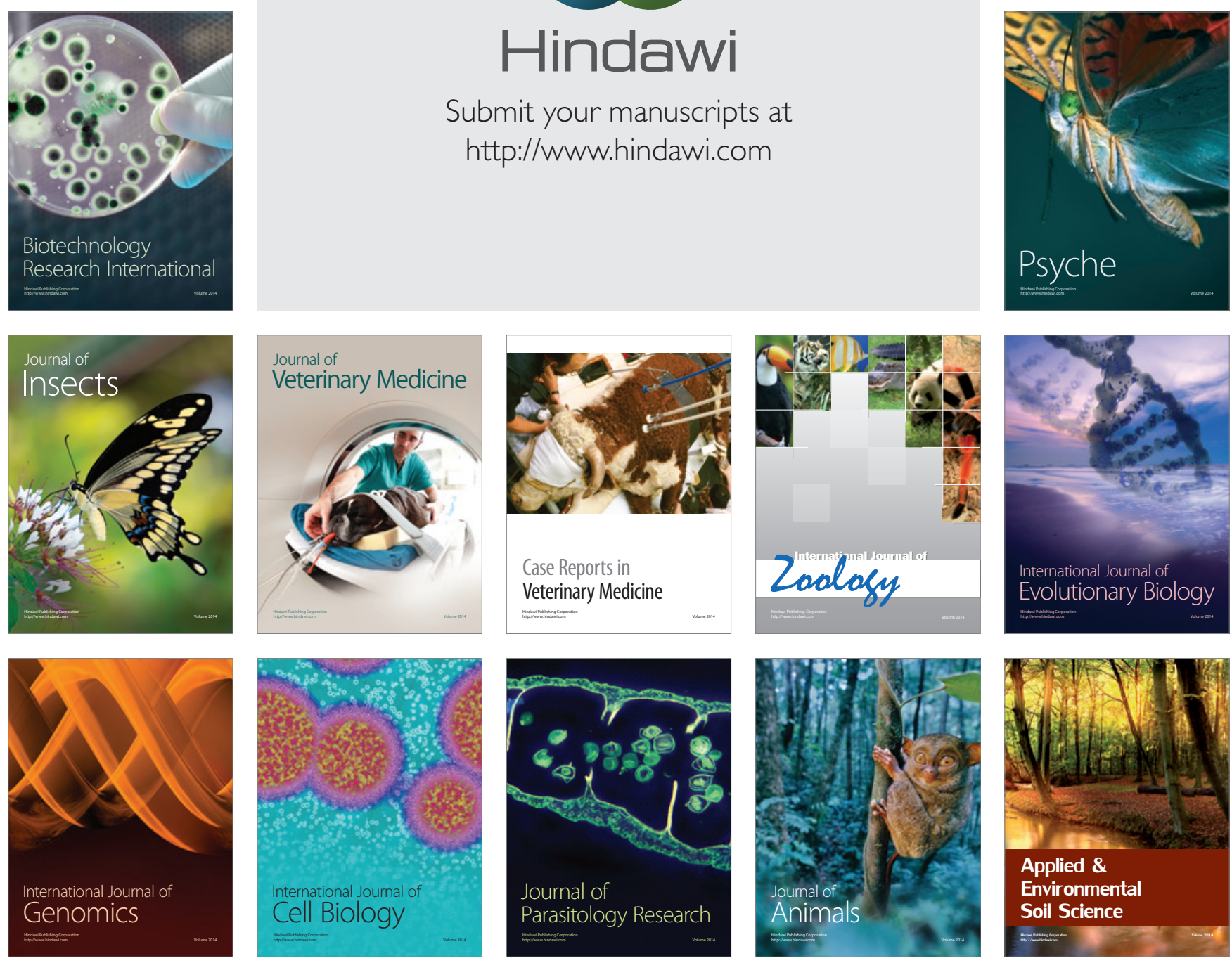